\title{
Herredsfoged Nis Henriksen paa Haistrupgaard og hans Slæót.
}

Geneologiske og personalhistoriske Bidrag, samlede af Dr. G. Friis.

Som Familiens Stamfader maa sættes Peter Petersen, $\left.{ }^{1}\right)$ der var født c. 1390 i Lændemark, Bylderup Sogn, og c. $1420 \mathrm{kom}$ i Besiddelse af Haistrupgaard, som der fortælles, ved Giftermaal, - Hustruens Navn er gaaet i Forglemmelse. Han havde straffet sin Karl for begaaede Uordner, hvorefter denne dræbte ham med en Økse ved en Aalegaard vesten for Gaarden. Han efterlod fire Børn, fra hans anden Søn, Nis, nedstammer Familien Esmarch, og blandt denne Families Medlemmer den bekjendte Kirurg Geheimemedizinalrath Professor Dr. med. von Esmarch i Kiel.

\section{Slægtled.}

Peter Petersens ældste Søn, Henrik Petersen arvede ${ }^{2}$ ) Haistrupgaard efter sine Forældre og nævnes i Løgumkloster Diplomatariet 1470 og 1500 (Ein godt tho Hastorp

1) Bilag I samt O. H. Mollers Bericht von verschiedenen Ländern, Städten und Gegenden des Herzogthums Schleswig. Skriftet er efter et Manuskript af Jonas Høier, Raadmand i Flensborg.

2) Udtrykket er ikke ganske nøiagtigt, se neden. 
dar Hinrick up wanth). Hans Hustru Ellen rar fra Vollerup, og med hende havde han fem Børn, af hvilke

\section{Slægtled}

Nis Henriksen ${ }^{1}$ ) (f. $1478 \dagger 1554$ er mest bekjendt. I lanske Herredsbreve (Løgumkl. Diplom.) kaldes han Nis Hierrissen eller Hierriksen, i plattyske Henricksen eller Hinricksen, først hos Moller (Jonas Højer) Hinrichsen. Han blev keiset og valgt til Herredsfoged i Slogs Herred 1518; 1523 mødte han paa Urnehoved Ting og søgte at faa den Frederik I. fjendtlige Bondehær til at skilles ad, idet han navnligen fastholdt, at Frederik I. nu havde Landet i Besiddelse, $0 \mathrm{~g}$ at Christiern II. først skulde føres tilbage, hrortil deres Magt vilde være altfor ringe. Hos en stor Del af Forsamlingen mødte han stærk Modstand, fra haarde Ord kom det til Haandgribeligheder, han blev haardt saaret, fem Pile bleve hængende i hans tykke røde Kappe, og han undslap kun ved Hjælp af sin rappe Skimmel, der hurtigt bragte ham bort fra det urnlige Ting og udenfor hans Modstanderes Rækkeevne, men da havde han opnaaet, hvad han havde kæmpet for, - Bonderne gik hver til sit. Kappen med Pilene tilligemed hans Sporer hængte i Bylderup Kirke til henimod Slutningen af forrige Aarhundrede. Barfod synes ikke at være tilfreds med Nis Henriksens Optræden paa Urnehoved Ting, - efter min Mening var hans Optræden fuldkommen korrekt, naar man sammenholder den med Datidens Tænkemaade. Urnehored laa par den Tid indenfor hans Herred, han var hertugelig

1) Moller paa cit. Sted. Bilag I. A. D. Jørgensen: Fyrretyve Fortællinger af Fædrelandets Historie. Barfod: Fortællinger af $\mathrm{F}$ drelandets Historie. 
Herredsfoged og havde som saadan intet at gjøre med Kong Christiern.

Begivenheden paa Urnehoved har Sagnet udsmykket paa folgende Maade, saaledes som det endnu fortælles her par Egnen om „den gamle Herredsfoged".

En Konge havde to Sonner, og da den Aldste ved Faderens Død var i Udlandet, bemægtigede den Yngste sig Tronen. Efter sin Hjemkomst vilde den Eldste ikke finde sig heri, og det truede med en Borgerkrig, da de bleve enige om at vælge $\mathrm{N}$. H. til Voldgiftsmand, og derfor sternede ham til at møde en bestemt Dag paa Urnehored Ting. Han havde en Skimmel, en udmærket Løber, som han nu fodrede med Simler og Mrlk, og efterat han endnu havde anskaffet sig en tyk og vid Reisekappe, kom han til den bestemte Tid ridende op paa Tingstedet, hvor begge Prindser med deres beræbnede Følge allerede vare ankomne. Han steg nu ikke af, men raabte saa høit, at det kunde høres over hele Tinget: „Landets Folk skal holde med Landets Barn", hvorefter han vendte sin Skimmel og sprængte afsted forfulgt af den ældste Prindses Folk, der beskøde ham med Pile, af hvilke fem bleve hængende i hans af Vinden oppustede Kappe. Han fortsatte sin Flugt, og da han var kommet et Stykke frem, var Veien spærret af en Vogn, som hosstaaende Folk, der kjendte deres Herredsfoged vilde trække til Side, men han raabte, de skulde lade den staa og satte hen over den. Noget længere fremme kom han til et lukket Led, som en Kone netop var i Færd med at aabne, da han raabte, at hun skulde lade det staa lukket, satte han over det og reddede sig ind i den bagved liggende Skov, hvor han holdt sig skjult, indtil Alt var kommen til Ro. 
Kong Frederik belønnede senere dog vistnok endnu samme Aar sin Herredsfoged for hans udviste Troskab, hvortil han vel kunde have Anledning, da N. H. havde ydet ham en væsentlig Tjeneste paa en Tid, da Kronen endnu vaklede paa hans Hoved. Dotationsbrevet er vistnok gaaet til Grunde, og Meddelelserne vedrørende denne Sag maa optages med nogen Forsigtighed. Jonas Høier (f. $1587+1640)$ siger, at Frederik I. gav N. H. Haistrupgaard fri og gjorde ham selv til Frimand, og hos Petrus Fabricius ${ }^{1}$ ) hedder det (1616), at hans Landsfyrste begavede ham med stor Frihed og arvelig Eiendom. Haistrupgaard var en hertugelig Fæstegaard, og det var den endnu under Sønnen Hans Nissen, til hvem den bortfæstes den 28. Aug. 1566 „saaledes som hans Fader fik den af Kong Frederik". Udtalelserne hos Høier og Fabricius kunne derfor ikke være ganske rigtige, - han kan kun have faaet Eiendommen som Arvefæster eller Arveforpagter maaske med Ret til at sælge og pantsætte.

Hvad det andet Punkt angaar, at han blev gjort til „Frimand“, kan Høier kun hermed mene, at han blev adlet ${ }^{2}$ ), men om han har Ret i denne sin Paastand, kan være et omtvistet Spørgsmaal, og det kan næppe interessere her at opregne de Grunde, der kunde tale for og imod, Sagen lader sig ikke afgjøre ved Hjælp af de Dokumenter, der for Øieblikket staa til Raadighed.

1) Bilag I.

2) Ordet "Adel“ forekommer første Gang 1524 i Frederik I.'s Haandfæstning. - Om Betydningen af Ordet „Frimand“ se bl. A. Geschichte des öffentlichen und Privat-Rechts des Herzogthums Schleswig von Stemann. I., Pg. 189 og Falck: Handbuch des Schlesw.-Holstein. Privatrechts. II. Kap. 4 $\S 34$. 
Familiens Mærke er den forreste Halvpart af en til Høire springende rød Hjort med en gylden Slange i Munden i hvidt eller Sølv Felt, - paa Hjelmen det samme Mærke, Hjelmdækkerne hvide og røde. Nogle have udeladt Slangen, saaledes den Gren af Familien, der gik til Lüneborg, ${ }^{1}$ ) 0 g hos nogle springer Hjorten til Venstre, - senere Generationer have føiet en Træoruppe til.

Da N. H. senere kom i Besiddelse af Vraagaard, der ogsaa var en hertugelig Fæstegaard, fik han samme Rettigheder for den som for Haistrupgaard, og fik Lov til til eget Brug at fælde Bygningstømmer og fede Svin i Hertugens Skove. Ogsaa andet Jordegods ${ }^{2}$ ) vidste han at erhverve sig hos Landsherren saa at det synes, at han har forstaaet at tale sin egen Sag, ligesaa godt, som han paa Tinget forstod at tale sin Hertugs og Konges.

I det Mindste indenfor Slogs Herred har han været en meget mægtig og anset Mand, ellers vilde Erindringen om "den gamle Herredsfoged" ilke have holdt sig til

1) Se Stamtavlen. Se Büttner: Genealogiæ oder Stammund Geschlehts-Register der vornehmsten Lüneburgischen Adlichen Patricien Geschlechter Lüneburg 1704, hvor der baade findes en Tegning og en Beskrivelse af Vaabnet: "Ihr Wapen war ein weiser oder silberfarber Schild und in demselben ein rechts sehender halbabgehakter rother Hirsch mit seinem Gehürn" o. s. v. - Paa Alterstagerne i Aventoft Kirke er Vaabenmærket for Karsten Hansen uden Slange, derimod for Sønnen Dethlef Karstensen med samme. - IOldtiden antog man at Hjortene vare Slangernes farligste Fjender (Plin. Hist. nat XXVIII, 9 og Joseph. Hist Jud. II, 5). Om Mærket indeholder en Allusion til den haardt saarede Herredsfoged, der maatte flygte fra Tinget, men knuste Oprøret, maa staa hen.

2) Bilag VI og Pg. 219. Et Fors $\varnothing g$ paa at erhverve den c. 154 Demat store Engstrækning "Thomaskjær" hos Hertugen glippede i sidste Øieblik. 
Nutiden. Endnu et Sagn fortælles om ham, men hvad der her ligger til Grund, er ikke godt at vide.

En Mand faldt i Aaen ved Rends, en anden Mand ilede til og vilde række ham en Stang, men var saa ubehændig at støde ham i Øiet. Han blev vel reddet men mistede Synet paa det paagjældende Øie, og anklagede nu sin Redningsmand for Legemsbeskadigelse. Nis Henriksem kunde ikke blive enig med sig selv om, hvorledes han skulde dømme i denne Sag, da han en Dag red over Jeising Banke og der saa tre Drenge, af hvilke den ene sad paa Diget ved Veien med et Hestedækken om sig, medens de to andre stode foran ham. N. H. holdt sin Hest an og spurgte, hvad de bestiite, hvorpaa han med Dækkenet sagde, at han var Herredsfoged, at de to andre vare Rendsere, at han var i Færd med at dømme dem imellem og lige havde dømt, at den Reddede skulde springe ud paa det Sted, hvor han havde været i Livsfare, og hvis han kunde redde sig selv, skulde han have Skadeserstatning, raabte han derimod om Hjælp, skulde hans tidligere Redningsmand være sagesløs. N. H. fandt denne Dom meget snild, gav „Herredsfogden" nogle Smaamønter" og dømte senere, som Drengen havde gjort. Det tilføies, at Udfaldet blev meget ulykkeligt for den Paagjældende, der druknede. Fortællingen minder en Del om en af Historierne i 1001 Nat.

Nis Henriksens Hustru Anna var fra Vellerup i Agerskov Sogn. Hvornaar han blev gift, vides ikke, maaske 1516, han blev nemlig selv optaget i Frue Kjøbmandslag i Flensborg 1515, - han besad Huse i Flensborg ---, og Fru Anna 1517. Af deres otte Børn ere de to rimeligris døde tidligt, i det der kun forekomme seks i Delings- 
akterne. I Bylderup Kirke findes en Ligsten, der efter Traditionen skulde have dækket झ̈gteparret, nu ligger den foran Prædikestolen under Mandfolkestolene, og det er derfor forbundet med en Del Vanskelighed at læse den iøvrigt tydelige Indskrift. Der staar: Anno domini MVCLIIII (Resten af denne Side er dækket af Træværk) word hier vnde begraven Nis Henricksen Hardesfaget dem Godt ane Twivel gnedig - Got min hogest Trost. - Paa Haistrupgaard findes en Glaspokal, paa hvilken man ser et rigtignok meget beskadiget Oliemalerie forestillende Nis Henriksen paa sin steilende Skimmel i sin flagrende røde Kappe. Paa den modsatte Side synes det, at Vaabnet har været anbragt. Er Billedet rigtigt i sine Enkeltheder, maa han have baaret et Harnisk under Kappen. Ansigtsudtrykket modsiger ikke Jonas Højers Dom: „Er war ein verschlagenes Weltkind“. - Desuden findes paa Haistrupgaard to Oliemalerier i Legemsstørrelse, - Traditionen vil vide, at det er „den gamle Herredsfoged “ og Fru Anna, men har næppe Ret, da Dragterne ere c. hundrede Aar yngre, det er maaske (?) Hans Nissen og Dorothea Stridebeck (se neden).

\section{Slægtled.}

Hinrick ${ }^{1}$ ) Nissen har formodentlig været den ældste af sine Søskende og var Borgmester i Tønder fra 1551 til 1560. Hans Hustru hed Marina og besad efter Mandens Død tilligemed sine tre Sønner den Bondegaard i Vollerup, som Nis Henriksen med alle sine Sønner havde efter Kong Frederiks Privilegium. Konfirmationen daterer sig fra 22./4. 1578 .

Peter Nissen førte en Proces med sine Søskende

1) Bilag II. 
om Vraagaard, som han vilde have forud, men han tabte Sagen. Han var gift med en Datter af Raadmand i Flensborg, Claus Frese, der anførte Flensborgerne i Grevens Feide og senere af Byen fik et Stykke Land skjænket, der endnu bærer Navnet Freses Lykke.

Hans Nissen (f. 1535, † 1575) fik Haistrupgaard og Vraagaard og blev seks Aar efter Faderens Død Herredsfoged i Slogs Herred. Hans Hustru Marin (Marine) var en Datter af en vis Peter Redlefsen i Tæxnder, og med hende havde han elleve Børn, af hvilke to maa være døde tidligt, der omtales nemlig kun ni i Delingsakten. ${ }^{1}$ ) Hans og hans Hustrus Navne med deres Familiemærker, - for sidstnævntes Vedkommende tre Trekløvere paa én Stilk, findes anbragte paa Prædikestolens Himmel i Bylderup Kirke.

Anna Nissen var gift med Jes Boysen paa Kollund, der var en Sønnesøn af den 1488 af Kong Hans adlede Jes Thomsen, om hvem der fortælles, at han senere i Slaget ved Hemmingsted overlod Kongen sin Hest, og selv greb fat $\mathrm{i}$ dens Hale. Jes Boysens Agnater afvekslende Peter og Nikolai have besiddet Kollund indtil 1872. En Stamtavle findes ikke.

\section{Slægtled.}

Nicolaus Heinrichs nedsatte sig i Lüneburg, var gift med Ursula v. Tobing og var efter Büttner „ein gelehrter und räsonabler Mann".

Nis Hansen ${ }^{2}$ ) (f. 1558, † 1616) arvede Haistrupgaard og Vraagaard og blev Herredsfoged 1591. Med sin Hustru Anna, der var en Datter af Herredsfoged Erich Clementzen

1) Bilag IV.

2 Bilag I. 
i Farensted, havde han tolv Børn, seks Sønner og seks Døtre, der alle overlevede ham. I Bylderup Kỉrke findes et Maleri af hele Familien samt deres Familiemærker, for Konens Vedkommende en bugtet Egegren med fire Blade og tre Agerner. Ved Siden heraf hans Stamtavle, omtrent det Samme som i Bilag I men mindre udførligt samt følgende Distikon:

\section{Epitaphium}

Integerrimi viri Nis Hansen prætoris Sluxhardensis.

Nis mihi nomen erat patrium, sed nisus Olympo

In Christo posui spemque fidemque meo, Cujus et auspicio sacro duce flamine vixi, Ut scirem cunctis posse placere bonis. Uxor cum sobole et fidi valeatis amici, In coelum nobis certa pacata via est.

$$
\begin{gathered}
\text { Johannes Mauritius } \\
\text { præp. Tunder, } \\
\text { ex affinibus intimus. }
\end{gathered}
$$

Karsten Hansen ${ }^{1}$ ) havde den Gaard i Vollerup, som Hinrick Nissens Enke og Sønner havde havt, - Sønnen Nicolaus var gaaet til Lüneburg, og de to andre' Sønner maa formodentlig være døde - Hans Hustrus Familie er ubekjendt, hendes Navn var Ingeborg, og hendes og hendes Mands Forbogstaver og Familiemærker, for hendes Vedkommende et Oksehoved, findes indgraverede paa Alterstagerne i Aventoft Kirke.

Anna var gift med Raadmand iTønder, Casper Petersen, og deres Datter Anna ægtede Provsten i Tønder, Joh. Mauritius, Forfatteren af ovenstaaende Vers.

Marie var gift med Hans Owsen i Rost, Herredsfoged i N. Rangstrul Herred, og Efterkommere have boet hans Broder i den nævnte By indtil for ca. 50 Aar siden. Hans Owsen wiclarz o's

1) Bilag IV og V. 
og Marie ligge begravede i Arrild Kirke, hvor en Del af deres Ligsten endnu er i Behold. Der staar paa den:

... Hans Owsen i Roest Herritzfo ... .

... udi sit 60 Aar salig i Herren hensovit ...

... Quinde Marin salige Hans Owsens ...

....udi hendes Aar salig i Herren hensor . . .

Fru Maries Familiemærke sés ogsaa paa Stenen, Hans Owsens er afslidt.

\section{Slægtled.}

David Heinrichs ${ }^{1}$ ) (f. 1595, † 1648) havde studeret ved mange forskjellige Universiteter $0 \mathrm{~g}$ blev Sülfmeister ( : Forstander for Salinerne), Borgmester og Raadsherre i Lüneburg, og var gift med Anna Marie v. Lüneburg, en Datter af Hertug August af Braunschweig og Lüneburg med Else Schmïedechen, der var en Borgmesterdatter fra Epsdorf, og var viet til Hertugens venstre Haand. - At denne Gren af Familien i Lüneburg er bleven anset for at være af god Adel, turde være utvivlsomt: at være Sülfmeister var et adeligt Prærogativ, og Anna Marie v. Lüneburg var vel det fornemste Parti i Landet. - David Heinrichs har sikkert nok været en meget anset og mægtig Mand. Han har skrevet en Disputats: De Nobilitate, og desuden en juridisk Afhandling. Med hans Sønner er rimeligvis Familien i Lüneburg uddød paa Sværdsiden.

Dethlef Karstensen ${ }^{2}$ ) (f. $1597, \dagger 1645$ ) var Forpagter

1) Büttner anf. St.

3) Bilag V. De ældste Kirkebøger her paa Egnen begynde 1653, men udmærke sig ved en stor Unøiagtighed med Hensyn til Aarstallene, undertiden ere Unøiagtighederne saa store, at det er tydeligt nok, at Kirkebogen ikke er holdt à jour, men lavet mange Aar efter Begivenhederne. I Aventoft Kirkebog findes saaledes, at Fru Kathrine paa Fogebøl er død d. 8. Jan. 1657, 69 Aar gl., og dog er det 
af den hertugelige Gaard Fogebøl (Fockebüll, Fuggebüll, Fugkebüll) i Aventoft Sogn, og var tillige Digefoged. Hans Hustru Kathrine var en Datter af Kjøbmand og Raadmand Anders Thomsen af den mægtige tønderske Familie Andersen eller Ambders, som den senere kaldte sig. Hendes Oldefader, Anders Momsen, Raadmand i Tønder, er bleven bekjendt ved, at han paa Veien mellem Tønder og S. Løgum i Nødværge dræbte Adelsmanden Erik Emmiksen af Tyrstrupgaard og derfor maatte rømme af Landet. Familiens Mærke var to Blade med Stilkene om en Træbul, imellem Bladene en Sol. Dethlef Karstensens og Hustrus Familiemærker tilligemed hans Forældres findes indgraverede paa Alterstagerne i Aventoft Kirke. Han døde i Lübeck paa en Reise.

Hans Nissen $(\dagger 1654)$ arvede Haistrupgaard og kjøbte 1639 „eine wüste Hufe, genannt Tunde" af Hertug Friedrich for „1200 Rchsth. in Specie“. ${ }^{1}$ ) Han blev Herredsfoged og synes at have været vel sét.af Hertugen, der 1638 gav bam Jagtret ${ }^{2}$ ) i Slogs Herred, hvilken Ret er bleven bekræftet af de følgende Herskere indtil den preussiske Jagtlov af 1872. Af hvilken Familie hans Hustru Mette har været, lader sig ikke bestemt afgjøre, men jeg feiler næppe, naar jeg antager, at hun har været en Datter af Prorst

sikkert, at hun er død i Marts 1636, 37 Aar gl. Der findes nemlig en Samling af Ligvers, forfattet af Præsten i Burkal, Mag. Andr. Ambders (Kathrine's Broder), over afdøde Slægtninge og Venner, betitlet: Tundersche unsterbliche Sterblichkeit. I. B. 1649 , II. B. 1675 . I Bind I findes Ligvers over Fru Kathrine, og hendes Dødsaar og Dag angivet som oven anført (Marts 1636).

1) Kjøbebrevet findes i Königl. Staatsarchiv i Slesvig.

2) Bilag VII. 
Joh. Mauritius i Tønder (hvis Hustru var hans Søskendebarn) og en Søster til Mag. Andr. Ambders's Hustru Margrethe. Ambders kalder Hans Nissen „mein Schwager", og Joh. Mauritius underskriver sig paa Nis Hansens Epitafium: ex affinibus intimus.

Anna var gift med Lorenz Nissen paa Oldemorstoft, Herredsfoged i Vis Herred. Han nedstammede fra en vis Henrik Lorenzen eller Jæger, som af Kong Hans 1484 havde erhvervet nogle Rettigheder til denne Eiendom, der skal være bleven beboet af hans Efterkommere indtil de seneste Tider.

Margrethe ægtede Præsten i Tønder, Richard Bennich, der døde som Klosterpræst i. Preetz og nedstammede fra Herredsfogeden i Ringenæs, Peter B., som 1488 var bleven adlet af Kong Hans. Familiens Vaaben var to sammenflettede Egegrene med fem Agerner.

Dorothea var gift med Digedommer Andreas v. Andersen, ${ }^{1}$ ) der var en Sønnesøns Sønnesøn af Herredsfoged i Kjær Herred, Anders Sønnichsen, som 1450 fik „Fribrev" af Hertug Adolf og 1452 "Adelsbrev" af Christian I. Skjoldet delt paa langs af hvidt og blaat, deri en springende Ulv af de modsatte Farver. Fra Andr. v. Andersen nedstammer den i Chr. Albrechts Kog levende Familie v. Andersen.

Da alle tolv Søskende ved Faderens, Nis Hansens, Død endnu vare i Live, er det rimeligt, at flere end de næunte have efterladt sig Afkom. I Bylderup Kirkebog

1) Pastor Nicolaus Esmarch i Klægsbøl har udgivet en Ligprædiken over ham: Spirituale Christianorum oder Leichenpredigt über Andream Andersen, Fürstl. Teichrichter im Gotteskoog (Psalm 73, 28). Lubecæ 1635 in 4te. 
findes forskjellige Personer, om hvilke det er at antage, at de høre til Nis Hansens Efterkommere om end ikke i første Led, saaledes Anna Nissen af Haistrup, der 13./10. 1677 blev gift med Theologen Joh. Anton Musæus og døde 1684, 35 Aar gl. Birthe Nissen af Haistrup, gift med Hans (Johan) Andersen paa Karlsvraa. Paa Vraagaard forekommer Marinus Nissen, og i Lysholm Dethlef Nissen. Det er bleven mig meddelt, at der i sin Tid fandtes en Hjort med en Slange i Munden paa en Stol i Burkal Kirke, der hører til den Gaard i Lysholm, som nu eies af H. P. Hansen.

\section{Slægtled.}

Hans Nissen (f. 1625 † 1681) arvede Haistrupgaard, blev Herredsfoged og var gift med Dorothea Stridebeck, hvis Familie er ubekjendt. Hun overlevede Manden i 56 Aar og blev efter hans Død indviklet i en Række Retssager vedrørende Gaardens Friheder, hvilke Sager hun udfægtede med stor Tapperhed og fik 1697 d. 6. Nov. af Hertug Frederik IV. de arrlige Udgifter ansatte til $34 \mathrm{Rd}$. og for det Øvrige ganske befriet "propter speciale meritum“. Hun synes i det Hele at have været en stemplet Dame, hvilket maaske har været Grunden til, at hendes tre Sønner henlevede ugifte. Hun blev gift, da hun var fjorten Aar, og hendes rldste Søn blev født, da hun var femten Aar.

Andreas Nissen fik Store Tønde og var gift med Hanna, en Datter af Pastor Paulus Claudius i Hostrup. Af Aktstykker, der findes paa Store Tønde ses, at han maatte udholde en langvarig Proces med den daværende Præst i Hostrup, Joh. Mauritius, vedrørende Tiendeafgifterne. Han vandt Sagen og staar i det Hele som den fredelskende Mand, der altid onsker Forlig ligeoverfor den 
stridslystne Præst, der tilmed var hans Svoger og vistnok ogsaa hans Søskendebarn.

Thomas Dethlefsen $\left.{ }^{1}\right)(†$ 1681) var født paa Fogebøl og opholdt sig her, indtil han af Hertug Chr. Albrecht 28. Marts 1662 beskikkedes til Landfoged i Bøcking Herred, 1669 blev han tillige Diggreve i Tønder Amt, hvilken sidste Udnævnelse kostede ham 500 Rchsth. til Regjeringspræsidenten J. A. Kielmann til Kielmannsegge. 1664 havde han en Strid med Herredsbeboerne angaaende en Afgift af 2 Sk. 1., der aarligt skulde ydes ham af hver Demat Land (j Alt 1400 Mk.), og endskjøndt han i denne Sag utvivlsomt var i sin gode Ret, maatte han dog give Regjeringspræsidenten en Gratifikation af 2000 Rchsth. for at faa Sagen i Orden. Allerede 1673 anklagedes han af Herredsbeboerne for at have hævet for mange Penge, men Klagen afvistes og der blev af Hertugen udstedt et Mandatum poenale, i hvilket Bøckingherrederne trues med en Bøde paa 40 Rchsth., hvis de vove at fortrædige "den Ehrsamen unsern Landvogt in Riesemmohr ${ }^{1}$ ) lieben und getreuen Th. D." Mandatet maa senere være bleven taget tilbage, thi 1676 klages igjen og denne Gang med bedre Held. Den 29. Marts 1675 kaldes D. endnu af sine Modstandere

1) Se Aventoft Kirkebog og Historische Nachricht vom Teichwesen und damit verbundenen Umständen das Amt Tondern betreffend durch Petrum Petreium, königl. dänischen Probst und Pastoren zu Garding 1740 (Manuskriptet findes i Rigsarkivet). Arkivrester af Bøckingherreds Arkiv. -Zeitschrift der Gesellschaft für die Geschichte der Herzogthümer Schleswig-Holstein und Lauenburg.

2) Riesemmoor er det gamle Navn for Bøckingherred. Bilag VIII. Om Mandatet har kostet en Gratifikation, er muligt, men kan ikke ses af Aktstykkerne. Da der igjen klagedes 1676 var Kielmann død. 
Landrogt, men den 7 . Decbr. s. A. der gewesene Landvogt, Diggreve blev han til sin Dødsdag, dog er han rimeligvis ikke bleven afsat som Landfoged men kun suspenderet, thi endnu den 22. Decbr. 1680 kaldes han i en Skrivelse fra Amtmanden i Tønder, Hans v. Thienen, Fürstlicher Teichgraf des Amts Tundern und Landvogt in der Böckingharde. Der nedsattes en Kommission formodentlig allerede 1676 for at undersøge Klagerne, og da den arbeidede med sædvanlig Kommissionshurtighed, naaede den at afgive sin Kjendelse den 31. Oktbr. 1681. Th. D. var da allerede død, men hans Bo blev dømt til at tilbagebetale 6909 Rchsth. 24 Sk. 6 Pf., der blev gjort Udlæg i Boet for denne Sum, og som det fremgaar af et Aktstykke i Herredsarkivet af 12. Aug. 1682, maa Fordringen være bleven dækket. Der blev beregnet 6 pCt. p. a., og omtrent en Trediedel af Summen hidrørte fra de paaløbende Renter. Samtidigen vare forskjellige andre inddragne $\mathrm{i}$ Undersøgelsen og da narnligen hans Svigerfader, Borgmester i Tønder (1674-1686), Peter Preuss, der tid.igere havde været Landskriver i begge Marskherrederne, hans Svoger, Borgmester i Tønder (1669-1674), Johan Preuss, der tidligere havde været Landfoged i Horsbøl Herred og endnu flere. At Thomas Dethlefsen paa forskjellig Maade har gjort sig ulovlige Fordele paa Herredsbeboernes Belsostning, fremgaar tydeligt nok af Kommissionens Undersøgelse; vaske ham rén kan jeg ikke, men det maa tjene til hans Undskyldning baade, at hans Kollegaer i Marskherrederne gjorde det Samme, og havde gjort det Samme før hans Tid, og at hans Foresatte, Amtmanden i Tønder (1666-1673) Bertram Pogwisch og Regjeringspræsidenten J. A. Kielmann, gave et meget slet 
Eksempel, og navnlig gik Sidstnævntes Bestikkelighed over alle Grændser ${ }^{1}$ ). Ogsaa synes det, at man paa den Tid har betragtet den Slags Lovovertrædelser med andre Øine end nu, og at man tilgav de Skyldige, naar de blot tilbageleverede, hvad de paa en uretfærdig Maade havde sat sig i Besiddelse af: Peter Preuss blev arresteret og domt i samme Sag, men var desuagtet Borgmester i 'Tønder til sin Død 1686! Th. D. var gift med Mette Marie Preuss, en Datter af ovennæunte Borgmester Peter Preuss og Lauretha de Bähr. Hun døde 25 Aar gammel i Barselseng i Tønder, hvor Provst Stephan Kenkel holdt Ligprædikenen, som han senere udgav i Trykken under Titlen: Die gekrönte Treu, Trostseule über den zwar frühzeitigen doch seligen Todt der im Leben hochbegabten nunmehro aber im 25 Jahres Alters d. 28. April dieses 1674 Jahres selig verschiedenen jungen Frauen, Frau Mette Marie Detleffs, des Edlen Hochweisen und wohl gelahrten Herrn H. Thomas Dethleffs ${ }^{2}$ ), dero regierenden Hoch-Fürste: Durchlaut zu Schleswig Holstein hochbetrauter Landrogt in der Böckingharde Herzallerliebste Hauss Ehre, welch: d. 7. Mai dies Jahres 1674 Christüblich in Tondern beigesetzt $^{3}$ ) worden, nachdem sie abermals war eines Sohnes genesen. Der kan herefter ikke være mindste Tvivl om, at Fru Mette Marie er død i det angivne Aar, men desuagtet finder man i Tønder Kirkebog, at Th. D. i $16 \% 7$

1) Som oven bemærket maatte Th. D. flere Gange betale ham store Summer og har vel saa taget Pengene, hvor han kunde faa dem.

2) Familien er i Færd med at antage et Stammenavn. Dethlef Karstensens Hustru benævnedes endnu Kathrine Dethlefs og Børnene Dethlefsen og Dethlefsdatter.

s) Hun er rimeligvis begravet i Dedsbøl. 
har ladet en Søn døbe Nicolay og i 1678 en Søn Johan ${ }^{1}$ ). Som det synes overlevede mindst fire Børn Moderen, af disse ere atter de to døde før Faderen ${ }^{2}$ ), i et Aktstykke fra 1681 omtaler Peter Preuss, at han maa forsørge to umyndige Børnebørn, formodentlig Nicolai og Johan (Hans).

Familien Preuss, hris Familiemærke var en rød Rose i Sølvfelt, paa Hjelmen to Vinger, derimellem to røde Roser, uddøde sandsynligvis 1705 med Peter Preuss's Søn Lucas. Om David Preuss, der blev Rektor i Tønder 1636, har været af samme Familie, lader sig for Øieblikket ikke bestemme. Det er rimeligt, at de to Barneportræter, der findes paa det store Epitafium i Tønder Kirke over Familien Preuss, ere af Mette Marie og Lucas.

Magdalene Dethlefsen (f. $1623 \dagger 1684$ ) var gift med Johan Preuss, Landfoged i Horsbøl Herred, de boede paa Fogehøl, Magdalenes Hjem, da han senere blev Borgmester i Tønder, boede de rimeligvis, hvor nu store Apothek ligger, og have de maaske opført denne Bygning, i etlivert Tilfælde findes dér en Sandsten med deres Familiemærker. Johan Preuss døde'1674, og Magdalene ægtede 1677 Dr. Nicolai Fries (eller Friese), der dog allerede døde 1679. Begge Egteskaber vare barnløse. Med sin første Mand harde hun oprettet reciprokt Testamente, og for at faa denne Sag bragt i Orden bler der anvendt 4000 Rchsth., af hvilke de 2000 gik i Regjeringspræsidentens Lomme ${ }^{3}$ ).

1) Kirkebogen i Tønder begynder for Daabslisternes Vedkommende 1653, men maa være lavet efter 1680, idet de der ere fødte efter 1653 men igjen døde før 1680, ikke findes der.

2) Se Tønder Kirkes Regnskab for 1677 og 1679.

3) Se Zeitschrift der Gesellschaft für die Geschichte der Herzogthümer. 
Som Joh. Preuss's Arving blev hun inddragen i den Tønderske Kommissions Undersøgelse og dømt til at betale 24,000 Rchsth., en Sum, der nu vilde svare til et Gods paa 400 Tdr. Hartkorn ${ }^{1}$ ). Denne store Udbetaling har formodentlig givet Anledning til et i Viding Herred meget. almindeligt Sagn. Hun skulde en Gang ved Veerladen have kastet en Guldring i Dybet og sagt, at ligesaalidt. som hun atter vilde faa Ringen at se, ligesaalidt kunde. hun nogensinde blive fattig. Sin polykratiske Ring fandt. hun senere $\mathrm{i}$ en Gjedde og døde i Fattighuset i Aventoft. Slutningen af Historien er nu i ethvert Tilfælde ikke ganske rigtig. Et Aktstykke i Horsbøl Herreds Arkiv viser, at Joh. Preuss's og hendes Arvinger endnu 1702 skattede af 62 Demat 25 Roder Kogsland, men selv uden dette Vidnesbyrd godtgjør Bilag IX, at Hertugen vilde have ladet hende tilflyde Understøttelse, hvis hendes Formue var gaaet tabt ved Udbetalingen.

I Aventoft Kirke findes et Epitafium med gode Portræter af hende og Joh. Preuss, med begges Familiemærkerog med følgende Vers i ganske letløbende Aleksandrinere:

Wer hier in dieser Welt die Ewigkeit betrachtet

Und Gott für seinen Schaiz im Leben achtet

Dem wird der Tod ein Schlaff und ein erwünschte Ruh Wenn er nach Gottes Scbluss thut seine Augen zu.

Der stirbt getrost und wohl, der in dem ganzen Leben

Der Sterblichkeit gedenkt und sich nicht will ergeben

Der eitlen Eitelkeit. Gott ist sein höchstes Gutt,

Die Welt liegt ihm zu Fuss in allem was er that.

Forfatteren er ikke angivet, man maa vel nærmest tænke paa Magdalenes Morbroder, Mag. Andr. Ambders i Burkal ( $†$ 1687).

1) Et Grevskab - 2000 Tdr. Hartkorn - blev nemlig 1670 vurderet til 120,000 Rd. cour. 
Ingeborg Dethlefsen ægtede Borgmester Hinrich v. Hatten $^{1}$ ) og var hans anden Hustru, idet han først var gift med Landfoged i Horsbøl Herred Jørgen Eckleff's Enke Dorothea f. Preuss, en Søster til Johan og Peter Preuss. Hans og Hustruers Vaabner findes anbragte paa Prædikestolens Himmel i Kirken i Tønder. Han var en Søn af den af Keiser Ferdinand adlede Landkantsler af samme Narn. Skjoldet red en Flod delt paa Tværs, for oven to seksoddede Guldstjerner, for neden én, paa Hjelmen en Krone, af hvilken to Morgenstjerner stikke frem.

I Høist Kirkebog findes: Nissenius Nissen fra Haistrup, f. $28 / 11624 \dagger 1705$ gift 1661 med Anna Claudius fra Hostrup, f. 18/11 $1645 \nmid 1705$. Af hvem Nissenius Nissen er en Son, lader sig ikke sikkert afgjøre, da han benæunes fra Haistrup, maa han vel være fodt der og han maa vel være en ældre Broder til Hans Nissen (f. 1625). Hans Hustru, Anna, maa være en Datter af Pastor Paulus Claudius og en Søster til Andreas Nissens Hustru, Hanna:

\section{Slagtled.}

Anna Sofie Nissen blev gift med Præsten Evald Ægidii, og det viser sig her, at forelskede Folk til enhver Tid have været lige naragtige. I Bylderup Kirkebog findes nemlig under 26. Marts 1673 anført: „Døbt Hans Nissens Datter Anna“, senere er tilføiet med Evald Egidii's Haand, Hans Nissens „deilige" Datter „Jfr." Anna Sofie. Agidii's Fader var Præst i Bylderup, og han var Faderen adjungeret - hans Broder var den som geistlig Digter bekjendte Bartel Christian, Præst i Varnæs, og hans Søskendebarn

1) Med Fru Ingeborg havde han to Døtre, der begge døde som Børn (Tund. unst. Sterbl.) og naturligvis ikke findes i Kirkebogen. 
var den bekjendte Waisenbuspræst i Kjøbenharn, Enevald Ewald, Johannes Evalds Fader.

Da Brødrene Hans, Johan Detlef, og Adolf Nissen vare døde ugifte, arvede Helene Marie Nissen Haistrupgaard, og da hun selv var ugift, solgte hun den 1743 til Herredsfoged Vilhadus Fabricius, og den gik saaledes ud af Familien, i hvilken den havde ræret gjennem otte Slægtled i c. 300 Aar. Den nye Eier solgte igjen Gaarden til Thomas Sønnichsen, og i hans Families Besiddelse findes den endnu.

Andreas Nissen arvede Store Tønde og. var gift med Elsabe Margrethe Ambders, en Datter af Præsten i Burkal, Chr. Ambders og en Sønnedatter af Mag. Andr. Ambders. Ægteskabet var barnløst, og ifølge reciprokt Testamente, konfirmeret 1720, beholdt Enken Eiendommen ved Andreas Nissens Død. Hun æotede senere den bekjendte Historiker Andreas Hojer, hvem hun medbragte Store Tønde. Han var en Præstesøn fra Karlum og døde 1739 som dansk Etatsraad, Generalprokurør og Prof. juris. Hans (Johan) Dethlefsen var født i Tønder, hans Fødsel kostede Moderen Livet, og da han i det syvende Aar tillige mistede sin Fader, er han formodentlig bleven opdraget hos sin Mormoder, Fru Lauretha Preuss. Hun døde 1697, og Hans D. har da for sin Arvepart kjøbt den Gaard i Arrild som han beboede til sin Død. ${ }^{1}$ ) Han var Sognefoged, fra $1 \% 09$ senere tillige Sandemand, - i Kirke-

1) I Arrild Kirkebog angives hans Alder til 68 Aar 6 Uger og 5 Dage skal være 69 Aar mindre 6 Uger og 5 Dage. I samme Kirkebog angives hans Hustrus Alder til $891 / 2$ Aar men da hun efter samme Kirkebog er født $16 \tau 2$ og døde 1657 maa det være $85^{1 / 2}$. 



\title{
Stamtavle.
}

\author{
¿ Peter Petersen, f. c. 1390. \\ Henrik Petersen levede 1500 , \\ g. m. Ellen af Volerup.
I! Nis Henriksen, f. $147 \%+1554$.
}

g. m. Annc af Velerup.

\section{Henrik Nissen, † 1560. Marine. \\ Nicolaus Heinrichs.
Ursula, v. Tobing. v. \\ David Heinrichs, f. $1595+1648$. Anna Marie v. Lüneburg.}

\section{Magdalena.}

1. Joh. Preuss.

2. Nicolai Friese.

Peter Nissen.
Claus Freses Datter. $\begin{gathered}\text { Kathrine. } \\ \text { Andr. Sonksen. }\end{gathered}$

Hans
1

Kissen, $1535+1575 . \quad$ Karstine.
Marie R Rlefsen.

Marie Ridlefsen. Hans Feddersen.

Nis Hansen, f. $1558+1616$. Heinr. Hansen.

Anna of Farensted. Anna Petersen. Casper Petersen. Andr. Jacobsen. Hans Owsen.

Han: Nissen II, $+\frac{1}{1645 . \quad \text { Anna. Margrethe. Dorothea. }}$
1

Thomas Dethlefsen, +1631. Mette Marie Preuss, $† 1674$. 1

Ingeborg.

Heinr. v. Hatten.

Hans Dethlefsen, f. $1674+1743$. Karen Nielsdatter (Larsen), f. $1672+1757$. 1

Marie Hansdatter Friis.

Joh. Erasmus Kiersing.
Mette (Mauritius). Lorenz Nissen. Richard Bennich. Andr. v. Andersen. 1

Hans Nissen III, f. $1625 \dagger 1691$. Clemens Nissen. Andr. Nissen, $\dagger 1684$.

Tette Kathrine. Anna Snfie. 3 ugifte $\mathrm{S}$. ZHeinr. Ibenthal. Evcald Agidii. Hanna . Claudius, $\dagger 1696$.

Mette Kathrine. Andreas Nissen. Rasm. Schmidt. Elsabe Marg. Ambders. 

bogen benævnes han Mons. Han var gift med Niels Larsens Datter af Rost.

\section{Slægtled.}

Niels Hansen Friis var født 1706 i Arrild $0 \mathrm{~g}$ blev 1736 Præst paa Fanø. Efter Traditionen skal han hare gaaet i Ribe Skole, hris saa er, har det kun været en kortere Tid, da han efter egenhændige Optegnelser, der findes i Præstearkivet paa Fanø, efter $4 \frac{1}{2}$ Aars Ophold hos Pastor Wöldike i Sommersted af ham er bleven demitteret til "Akademiet". Hvorfra Hans Dethlefsens Børn havde faaet Navnet Friis, lader sig nú ikke bestemt afgjøre. Hans Dethlefsens Broder, Nicolai, var holdt over Daaben og vistnok opkaldt efter sin Fasters Mand, Dr. Nicolai Friese (eller Fries), og det er jo altid muligt, at han har kaldt sig Nicolai Fries, og at Navnet paa den Maade er kommet ind i Familien. Niels Friis var første Gang gift med „Seignieur" Peder Nielsen Endorph's Datter paa Hennegaard, Jfr. Ide Sophie Endorph, der døde i første Barselseng med et dødfødt Barn. Anden Gang med Jfr. Anna Benedicta Kurtz, der ligeledes døde i første Barselseng med et dødfødt Barn. Tredie Gang var han gift med Jfr. Agnete Cathrine Stensen, der føclte ham ti Børn. Hun var en Søster til Etatsraad Steen de Steensen paa Aunsberg, der bl. A. er bekjendt fra Blichers Noveller.

Der lever endnu Efterkommere af Niels Friis - bl. a. er Meddeleren han Sønnesøns Søn. 


\section{Bilag.}

I.

\section{Brudstykke af Mag. Petri Fabricis Ligprædiken over Nis Hansen $\left.{ }^{1}\right)$ I6I6.}

Den allerførste, som man ved noget aff at sige, haffuer hædet Peder Pedersen, huilken haffuer begiffuen sig fra lendemarck fast for Tohundre Aar oc paa dette Sted i Haistrup sin liffstid hafft sin Bolig, men er af sin egen Suen vester Haistrup ved en Aalgaer, at han haffde tilbørlig straffet hannem for sin Moduillighed, med en Boløxe ihielslagen. Denne haffuer ladet efter sig fire Børn, huilke saaledes hafuer formeret sig, at af dennem er udsprungen offuer de 600 Siele. Efter hannem haffuer sin Søn Henrik Pedersen boet paa samme Sted og hafft sin Hustru Ellen af Wolderup, med hende afflet fem Børn. Dennes Søn Nis Henriksen fød 1478 haffuer i lige made boet effter sin Fader paa dette Sted. Hannem haffuer Gud saaledes ophøiet, benedidet oc velsignet, at han med Rett maa kaldes denne gandske Slectes Olderfader, første Oprindelse, Ere oc Priiss. Thi effter Gud haffde besønderlig begaffued ham med Vissdom, Fornufft oc Forstand, er han i sit 40 Aar 1518 keest oc vdvalt til Herritzfoged her i Sluxherrit men 4. Aar dereffter A. $1522^{2}$ ), der Kong Christiern bleff fordreffuen udaff Danmarck, haffuer han været paa Vornhoffuet Møde oc der med sin Frimodighed oc Forstandighed forhuerffuet saadan Gunst hos sin naadigst Landzførst oc Herre, at han haffuer begaffuet hannem med stor Frihed og arffuelig Eiendom, huilket sine Børnebørnsbørn endnu formedelst Gudz oc førstelig Naadis besønderlig Gunst oc Mildhed besidde, nyde oc bruge. Hand er død den neste Mandag for S. Andresis Dag oc afflet. med sin Hustru Anna aff Welderup udaff Affuerskou Sogn 8 Børn, af huilke er udsprydt 150 Personer. Hans Søn Hans Nissen fød 1535 traad $i$ sin salig Faders Fodspor icke allene paa sin Bolig meu ocsaa Embedis oc Forstelig Gunst og Naadis vegne. Friede Maren Peder Redleffsens Daater af Tunder A. 1555 i sit 20 Aar, worde Herritzfoget 1560

1) Oprindeligen trykt i Hamborg, nærværende efter en Afskrift i Rigsarkivet i Kjøbenhavn, tagen af Olaus H. Moller.

2) Det var 1524 . 
i sit 25 Aar, saa at imellem sit oc sin Faders Fogdy forløbe 6 Aar, døde 1574 d. 31. Martii, haffde afflet 11 Børn, de der haffue formeret sig over de 81 Siele. Hans salig Hustru Marin Hansis døde 1594 den 18. Februarii. Deres ældste Søn Niss Hansen, fød 1558 det næste Aar for dytmarsk Slag d. 1. Novembris Klocken 11 for Middag, bleff holden i nogle Aar i Tunder til Skole, dereffter i sit 13 Aar sendt til Lønborrig ${ }^{\mathbf{1}}$ ), der han haffuer været hos den gamle høilærde Mand Luca Lossio i sit Hus og ved sit eget Bord i 3 Aar. Der han var 16 Aar, haffuer sin Fader selff ført hannem til Hamborrig i den tydske Regneskole; paa samme Reise blev sin Fader siug oc døde strax dereffter. Derpaa haffuer sin Moder hjemfordret hannem igjen i sit 16 Aar, oc derefter været hos hende i 14 Aar, til hand var 30 Aar gammel, da haffuer han fried salig Erick Clementzens Herritzfogeds Daater Anna i Farensted, 3 Aar dereffter vorden Herritzfoget i sit 33 Aar, saa at han haffuer været Herritzfoget i 25 Aar, leffuet med sin Hustru 28 Aar, afflet med hende 12 Børn, 6 Sønner oc 6 Døttre, som endnu alle ere i liffue oc seet udaff sine 2 ældste Døttre 6 Planter udspryde. Han døde d. 8. Februarii Klocken 1 Effter Middagen 1616.

II.

\section{Nis Henriksens Arvinger tilskøde deres Medarving Hans Nissen deres Andel i Haistrupgaard og Vraagaard 1557. ${ }^{2}$ )}

Ick Kerstenn Jacubsen, hardesfaget vnnde dingshörer in Sluxharde, mathies Nyssenn, Tüge swensen vnnde Jes tüchesenn sanntmenne darsüluest bekennen vnnd betügen apenbar vor alsweme mydt dyssenn vnnsrenn apenn dingiswinde, de enhe Szeenn adder hörenn lezen, datt am Jare na die gebordt Christi dusen viffhundert in deme söuen vnnde vefftygestenn des mydtweckenns na reminiscere Erschenen vor vns vnnde gemeynen hardislüdenn, so des dages to dinge werenn, binne veher dingestocke ein besetenn vnnde uprichtygenn rechtes Ersame Hinrick Nyssen borgermeyster der Staàt lütcken Tundern vnnde ock de vorsichtige Anndres Sünnichsenn, Hans Feddersenn Borger vnnde Inwanere der Stadt Flennsborch vnnde ock de Ersame Jes boysen, arffgesetenn to Collundt, mydt wyllenn vnnde Fulbort erer doget-

1) Lønborrig c: Lüneburg. Lucas Lossius var en bekjendt Skolemand.

2) Det paagjældende Pergament er i Hr. Sönnichsens Besiddelse paa Haistrupgaard, ligesaavel som Pergamenterne til Bilag I, IV og VIII. 
samenn husfrauwenn genennet Katherine Anderses, Karstine Hannses vnnde Anne Jesses, vnnde se hebben aldar apenbor binnen veer dyngestocken vorschotet, vorlaten vnnd vorkoft deme Ersame Hanns Nyssen to Haesdrup wonaftig erbe gerechtigen egendome vnnde anpart ${ }^{1}$ ) so ein Jeder dersuluigenn na erenn szeligenn vader Nys Hinricksen ock eren moder, so datt mael im leuende was, mydt wyllen vnnde vulborde rechtes halleuen aruenn, krigenn vnnde erlangenn kenndenn inn de ghebuit vnnde huseninge to Haesdrup vnnde ock to wragardt alze de nemlich husze, schuene, spiker vnnde stellinge mit sampt allenn farendenn haus, dor idtz gemelt Hanns Nyssen op wonet, vnnde sin vader Nys hinricksenn szeliger gedechtnisse by sinem leuende bewanet hadde, darbenenenn ock ein bundengude to buldrop mydt alle sine bewolicke tobehöringe hus, grundt, ackerenn, wysche, weyde beneuen allent wes van oldinges dorto gelegen heft auer dat gantze buldrup velde belegen nichtes vnntagen, dorbeneuenn ock twe seermarck, datt ein osten Wragardt belegenn omme besteniget, datt andre in Hunding veltmarcken belegenn ock omme besteniget, vorschotede vnnde vorhetenn updachte Hanns Nyssen alles wo bawen geschrewenn in rnnd mydt kraft desses breues vor enenn vnnde ereun aruenn Hans Kyssenn vnnde sinenn aruenn frye vnnde quidt vor allen anspröeche vnnde to drenn follegenndenn dingenn vor schöet vnnde na schöet recht vande redelickenn lachbaden vnnde heft dorup binnen IIII dingestocken sin lachenet bekamenn vnnde erlanget na lanntrecht, vnnd se danckede deme ersame Hanns Nyssenn vor gude nogeaftige Aufschifftinge vnnde vullenkamener betalinge, wo dytt alle vorgeschrewenn, begerde Hanns Nyssen ein dingeswytlicheit des wurden dar VIII Framenn lüdenn ut deme Harde utgenennet alze benemlich, Jes Riggelsenn to Sotrup, Asmus Hannsenn to Eggebeck, Nys Jepsenn to Raepstede, Negels Petersenn to Buldrup, Nys Christiernnsenn to Therkelsbül, Peter Jennsenn to Quernnholt, Nys Johannsenn to Woldrup vnnde Christiernn Anudersenn to Heytze, de denne der wegenn vtgingenn rechtes halleuenn sich besprekenn wolbedachtes modes. Se semptlich binnenn veher dingestocke des ergeschreuenn hardis wedder inquemenn, tügedenn vnnde bewindedenn by erem warenn woerden gelouenn vnnde szelenn salicheit, dati alle puncten stückenn vonde articulenn synn alzo gegaenn vande gewarenn, alze vor geschrenenn, des in orkundes latenn wy up-

1) Gik naturligvis kun paa Bygninger og Løsøre, ikke paa Landet, da baade Haistrupgaard og Vragaard paa den Tid endnu vare Fæstegaarde. 
meltenn vagit vnnde sanntmenne vnsenn gewoentlichenn ingezegelenn wytlichen heten hengenn op spatium desses breues. Actum et factum in Sluxharde anno et die quibus et supra.

\section{III.}

\section{Paa Hinrick Petersens Vegne tilskøder Jacob Boysen 1562 Hans Nissen Haistrupgaard og Vraagaard.}

Ick Hanns Tarstennsen to Buldrup wonafftich sanntmanne in Sluxharde in des hardeffagedes stede in Sluxharde dynnge to holdennde verordennt, De Erbarrenn vnnde Errenntvestenn Erick Langen, arffgezetene to sollyck, Swenenn negelsenn vnnde Jes tücksenn ock sanntmane dorsuluest Bekennenn vnnd betügenn apenbar vor alsweme myt dyssenn unnsenn apen verzegeldenn dyngeswinde, datt am Jare na Christi unses herenn geborth vefftegen hundert vnnde in deme twe vnnde söstygestenn des mytwekenne na Estomihi, welcker is denn 11 dach des manes February, dann is vor unns vnnde gemeynenn hardeslüdenn, so des dages to dynnge werenn bynnenn veer dyngestockenn eynn besetenenn vande uprichtedenn rechtes personnlich erschenenn de Ersame Hanns nissen to hasterup wonafftlich, Esschede vnnd krech eynn fullenkamenn dingiswinde vann achte Framenn hardeslüdenn alze benemlich mickel Kragh vnnde Jes hannsenn to Büldrup, hanns Jepsenn to westergardth, Iwer Hannsenn in de Niemöle, Kristenn anndersenn to heytze, mickel anndersenn to Rapstede, Laurenns Kallesen vnnde Nys Patersenn to Renntze, de dor vtgingen rechtes haluenn sick to besprekenn wolbedachtes modes. Sze 'semptlichenn bynne veer dyngestockenn des ergeschreuen hardes wedder Inquemenn, tügedenn vnnde wyndedenn by eren worenn woerdenn gelouenn vnnde szelen salicheyt: Datt sze sehenn vnnde hoerdenn in egenen personenn jegenwerdich denn de ersame vorsichtige Jacub Boysenn, borger vnnde inwanere der Stadt Flennsborch, was personnlich bynnen veer dyngestocken des bauengeschreuenn hardes erschenenn eynn fulmechtyger vann wegenn vnnde ut beuele dem vorsichtygenn Claues fresenn, borger vnnde raetmanne der vpgemeltenn stadt Flensborch vnnd synes dochter Kinde genennet hinrick petersenn, dewyle de bauengemelt Claues fresenn to dersüluige tytt suach vunde krannk geweseun is, hefft Jacub boysenn de fulmacht gehatth Hanns nissenn eine usgrafftige schoet to geuende, vnnde he hefft al dar bynnenn veer dyngestockenn vann wegenn Claues fresenn vnnde synes dochter kindhe Hynrick petersenn, na inholde vnnde meldynnge synes verdrachtes breue, to welckere verdracht deme upgemeltenn 
Claues fresenn vnnd Hanns nissenn vann durchlüchtygenn K. M. to Dennemarcken hochwysenn redenn henngewyset, vnnde henngesettet synnth, apenbar verschoetet vnnde verlatenn deme vpgemeltenn Ersame Hanns nissenn alle de gerechticheyt, egenndom vnnde annpart sze datt kindt genennet Hynrick petersenn vann wegenn vnnde in stede synes selygenn vader peter nissenn allenthaluenn aruenn vnnde kregenn konnde to Hasterup, dor itze up wanet Hanns nissenn in husening, saet, qnick, gelde vnnde in allenn bewechlichenn vnnde unbewechlichenn güderenn nichtes entagenn darbineuenn des kindes anpart in eynen bundenngude to Buldrup ann hues vnnde grunt mytt alle syne gruntliche vnnde bewylliche tobehörynnge darbineuenn de huseninge vnnde gebuyte to wragarth sampt eynn seermarck in wragart feltmarkenn vmme bestent vnnde eynn seermarck in hundyungh feltmarckenn ock vmme besteenth, verschotede deme bauengemelten Hanns nissenn vnnde synenn aruenn in vnnde myt krafft vnnde macht desses breues frye vnnde qnidth vor allenn annsproecke, de nu synn vnnde hyrnamale kame werdenn vnnde to dreen follgendenn dynngenn vor schoet vnnde na schoet recht vnnde redelichenn lachbadenn synn Jachenet bynnenn veher dyngestockenn bekame vnnde erlannget na lanntrecht, vnnde Jacub boysenn hefft vann wegenn Claues fresenn vnnde synes dochter kinde hynnrick petersenn deme upgemeltenn Ersame Hanns nissenn bynnenn veer dyngestockenn bedancket vor gude nogeaftige Auffschifftinge vnnde fullenkamener betalinge na vader vnnde moder vnnde sonst allenhaluenn. Des in orkundes laten wy erstmals bawenschreuenn unnsenn gewoentlichen vande arfflichenn inngezegelenn wytlichenn heten henngenn vnnde henngenn laten up spatium desses berichts. Datum anno ut supra.

IV.

Et Pergament-Aktstykke fra Haistup fra Aaret 1592 indeholder et Skøde fra Hans Nissens Arvinger til deres Medarving Nis Hansen paa Haistrupgaard og Vraagaard. Det er en daarlig Haandskrift, Blækket er afbleget, ja paa større Partier helt borte. I 5 te Linie fra oven nævnes Sandemændene Jes Carstenss tho Stade, Andres Martenss tho Nolde vnd Christen .... to Biolderup - - hebben semptlich binnen veer Dingestockenn - - o. s. v. I 7 de Linie nævnes Arvingerne Heinrich Hanss binnen Flensborch, Carsten Hanss tho Wolderup, Laurenns Hanss vnd Jens Hanss gebroedern (?) to Haistrup. I 8de Linie staar: wolgelehrte, achtbare vnd vornehme Hr. Andres Jacobss Pastor 
tho - - Casper petersenn Radsverwanten der stad Tundern Hans Owsenn tho Rost, disse maa være Hans Nissens Svigersønner, da der i Linien neden under nævnes deres „leuenn husfrauwenn", med̃ hvis Fuldmagt de altsaa ere mødte (vor sze vnnd szenenn leuen Husfrauwenn), og hvis Navne ere: Anna Jespers, Kathrine Andress og Marie Hanss. Længere nede Lin. 14 staar: Nichts butten bescheden, wann alles, whes ehr szelige Vader Hans Nisss in siner Bruckung gehadt vnnd Niss Hanss noch in siner (Lin. 15) bruckung vnnde besith hefft mit alle freyheit vnnd gerechticheit verschoetet vnnd verkofft ock frywilligenn owerlaten Niss Hanss vand sinen ehrwenn o. s. v.

V.

\section{Dethlef Carstensen tilskøder Calle Poulsen og Hans Matthiesen Mikkelskrog $1627 .{ }^{1}$ )}

Ick Hans Nissen Hardesvaget in Schluxharde, Jep Jürgensen vnde Jes Nissen Santmanne dersuluest dhon hirmitt Offentlich kunt, Dat huden Dato nha der heilsamen Geborth Christi im 1627 Jahre Dingesdages den 16. January von uns vnde den gemenen anwesenden Hardesluden gehegedes Rechten, Erschenen de Erbar vnd Vornehme Detleff Carstensen op Fuggebüll, Sel. Carsten Hansen Weilant tho Wolderup Erffgeseten, nagelatener Sohn. Vnd hefft dersuluest mit frijem Willen vnd wollbedachtem Moede vor sich sowoll an stath sinen Leuen Moder, Ingeborch Carștenss, vnde sinen andern sembtlichen Mederuen Brödern vnd Schwestern vnd eren Allerorts Eruen vmb ehren betern Nutz vnd Notturfft willen tho einem ewigen vnwedderroplichen Erffkoepe vorschötet, vorlett vnd awergifft krafft disses den ock Erbaren Calle Pawelsen vnde Hans Matthisen beide tho Schmedeacker vnd ehren Eruen eine Stücke Landes effte Ornum twischen Wolderup, Bredewadt vnd Schmedeacker Veltmarcken belegen alse solch itzund in ein Sehrmarck afsonderlich umbgestehnet vnd mit Dicken vorfehtet vnd vorhenne tho Sel. Carsten Hansen Gude belegen gewesen, Mickelskrog ${ }^{2}$ ) genömet, henferener na Schmedeacker tho ehrem Gude tho kohren vnd to gebrucken. Dess Alles Detlef Carstensen vor sich sinen Moder vnde Süttschen vnd dehren allersits Eruen gebaren vnde angebaren ehnen Calli

1) Det paagjældende Dokument er smukt kalligraferet paa Pergament og er i Gaardeier R. Clausens Besiddelse i Smedager.

2) kaldes nu Carstens Lykke. 
Pawelsen, Hanss Matthisen vnd ehren Eruen ock gebaren vnd vngebaren, nöghaffter betahlinge haluen bedancket vnd vor alle vernere An vnd thospröke vullenkamlich quiteret. Also dat mehrbemelte Calle Pawelsen vnd Hans Matihisen vor sich vnd ehren Eruen vnd Nakahmenden gedachte quit vnd Lücke gelick ehr egen Erue henforner tho ehrem Gude quit vnd fry ahne alle beschwerde thogeneten gebruken vnd beholden schollen mechtig sin darmit tho dhon vnd laten ehresgefallens ahne jemandes bewehr vnd Insage. - Vnd wehlen vorbenohmede Erue tho dre Vnderschetlichen Dingdagen vor vnd na der Schöte Lachgebaden, vnd von nemande Wedderspraken -, Alss hebben de Erbaren Jens Hansen tho Wolderup, Boy Rossen tho Egbeck vnd Jürgen Jürgensen tho Rentz Olthergebrachtem gebrucke vnd Hardesrechte nha, ehnen den vullenkamen Egendhom darup gedahn. Dass alles Calle Pawelsen vnd Hans Matthisen ein Dingeswinde geeschet, so ehnen dorch acht Nageschreuene Hardeslüden is vergunth worden, alse mit Nahmen Andres Jürgensen, Ross Hansen tho Nolde, Jep Jepsen tho Burkarl, Andres Hansen tho Stemmelt, Niss Dinnisen tho Hunding, Christen Hansen tho Höist, Jes Callisen, Ouwe Jessen tho Rapsted. Desuluen betügeden, dat sich Alles vorgeschreuener Maten thogedregen. - Orkuntlich mit vnser ermelter Hardeffagets vnd Santmanne Insegelln bekrefftiget. Actum anno \& die ut supra.

\section{VI.}

\section{Brudstykke af en Ansøgning af 17. Sept. 1605 fra Nis Hansen paa Haistrnpgaard til Hertug Johan Adolph om Arvefæste paa nogle Enge. ${ }^{1}$ )}

- - - - Weill nun Gnediger Fürst und Herr meine Voreltern E. F. G. hochlöblicher Christmilder gedechtenis Löblichen vorfahren, Königen zu Dennemarcken vund Hertzogen zu Schlesswigh Holstein (ohne rumb zu melden) getrewlich mit Darstreckung Leibs und bluts gedienet, Indehme alss sich die aufrohrischen Bawern aus allen Embtern dess Herzogthumbs Schlesswig bey Uhrenhouet versamblet vorhabens KönighChristiern bey die Regierunge zu erhalten, Mein Grossvatter aber dasselbige gewehrett, worüber mein Sehliger Grossvatter Todtlich verwundet Vnd in gefahr Leibs Vnd lebens geraten, Dennoch aber gedachten aufrohr gestillet, wessfalls sich den diese sonderbare begnadunge nebenst anderen mehr freiheiten verursachet.

1) Aktstykket findes i Königl. Staatsarchiv i Slesvig. 
VII.

\section{Hertug Friedrich tildeler 1638 Hans Nissen Jagtret i Slogs Herred.}

Wir von Gottes gnaden Friederich, Erbe zu Norwegen cet. thun kundt und bekennen hirmit für Unss und unsere Nachkommen in der Regierung gegen Menniglichen, das wir dem Ersamen unserm Hardesvogtt in Schlugsharde vñd lieben getrewen Hans Nissen zu Haistorff wegen seiner biss dahero zu unserm gnedigen Contenti verspürten vnterthenigen Getrewen Dienste, die er auch continuiren soll kann und will, die Hasen und Fuchs Jagdt nebenst dem Vogel Schiessen auf denen in Schluxharde belegenen Manckgüetern und wo anders ausserhalb was zu Jagen befugt in gnaden gegeben und eingereumet haben, also und derogestalt, das Er, Hans Nissen, so lange er lebet, und wehr nach seinem Todte den Hoff von seinen Erben bewohnen wirdt, (dan allemahle nur einer und zeit die Besitzung des Guetes, des Jagens und schiessens Freyheit zu.erfreuen haben soll) die Jagdt gerechtigkeit gebrauchen mögen. Geben demnach und Concediren ihme, unseren Hardes Vogtt, und nach dessen Todte Einem seiner Erben und zwarn dem Besitzer des Guetes Haistorff, wie obstehet, auff vorerwehnten in Schluxharde belegenen Manckguetern Mit vinden und hunden Hasen und Füchse zu jagen und Vogel zu schiessen, und also frey und Mennigliches ungehindert zothaner Jagt und schiessens zu geniessen, Jedoch dass sie unserm Gehege nicht zu nahe kommen sollen. Unserm Landrath und Ambtmann zu Tundern, welcher itzo ist oder künfltig sein wirdt, hiemit gnediglich anbefehlend Vielernannten unsern Hardesvogt und dessen Mittbeschriebene bei dieser unser Concession zu schützen unu sie dawieder keinesweges beschweren zu lassen. Urkundtlich unseres handzeichens und aufgetrückte fürstlichen Secrets. Geben auf unserm Schloss Gottorff d. 1. Martij do. 1638.

Friedrich.

\section{VIII.}

Mandatum poenale an die sämbtliche Eingesesssene in Bøckingharde Tunderschen Ambts - pro Thomass Dethleffssen Landvoigt darselbsten. ${ }^{1}$ ). Wir von Gottes Gnaden Christian Albrecht, Erbe zu Norwegen cet. fügen den sembtlichen Einwohnern der Boekingharde hiemit zu wissen, dass uns der Ehrsame unser Landtroigt in Riessemmohr und lieber getreuer Thomas Detleffsen Supplicando unterthänigst zu verstehen ge-

1) Aktstykket findes i Böckingherreds Arkivrester. 
geben, welcher gestalt sich verschiedene Eingesessene derselbesten sich gelysten liessen wieder die usantze und dem her komen Einige Neuerungen vorzunehmen insonderheit von demjenigen wass in beysein 20 oder 24 Persohnen Hardes Ge Vollmechtige Rathleute vnd Teich voigten bereits berechnet worden, neue Rechnungen undt Abschriften zue fodern. Imgleichen alles nach Ihrem eigenen belieben zu censiren, kein Bedenken trugen, vnd dahero umb Unssern Mandatum Poenale dessfalls gehorsambst gebeten, welches auch heute Dato gerichtlich erkannt worden.

Befehlen demnach allen vnd Jeden Eingesesssenen in gemelte Böckingharde hiemit gantz ernstlich und zwar einen Jedweder so dawieder wirdt handeln bey Funfzig Rchsth. Uns unnachlesslich zue erlegender Poen wollende, dass Keine von den Eingesessenen, Er sei wer Fr wolle, sich binfürter solle gelüsten lassen gedachten Unseren Landvoigten, Thomass Dethleffssen, wen die berechnungen von demselben dem alten her Komen gemäss in gegenwart 15-20 od. 24 Persohnen alss Hardes ge-Vollmechtigen Rathleuten vnd Teichvoigten geschehen, mit keinem vorwitzigen und in anderen Harden ungebrauchliche Abschriften undt Neuerungen der schohn bereits formblich beschehenen berechnungen hinfohrt weiter zu behelligen, oder sonsten einigen Gestalt zu beschweren, so lieb einem Jeden oben gedeutete Brüche zu vermeyden. Wornach sich ein jeder zu achten und für schaden zu hüeten. Geben auff unsseren Schlosse Gottorff d. 11. Febr. Ao. 1673.

L. S.

Christian Albrecht.

IX.

\section{Marginalbemærkning paa den tønderske Kommissionserklæring af 31. 0kt. I68I. ${ }^{1}$ )}

Ihr o Hochfürstil. G. lassen geschehen, dass der Unterthanen wegen ibrer Prætensionen in bonis viduæ den Vortrit vor dero fisco geniessen, gestaltsamb der H. Ambtmann dahin Committiret wird demselben Executive in specie auch den Schluxhardern wegen ihren verschlossenen v. an noch nachstehender Contribution wegen des Guthe's Wollderup als ihre Specialunterpfandt zu ihrer Gerathsame zu verhelffen, v. halten Ihr F. G. derselben bevor, wieweit Sie an der unterthanen Prætension Participiren wollen, wie auch in ratione dero eigenes interesse contra viduam zu folge ihres d. 4. Julii Ao. 1681 gethanen ablati Competentia, wenn auch gleichwoll Ihr F. G. auss ange-

1) Horsbøl Herreds Arkivrester. 
borner fürstl. clementce der Wittibe Ihr Nottürfflige unterhaltung gndgst gönne, alss wirt der H. Ambtmann fordersambst referiren, wie und welcher Gestalt $\mathrm{Er}_{\mathrm{r}}$ nach Befriedigung der Unterthanen die Gütter der Wittiben befinde, worauff sie ferner in Gnaden resolviren und respective derselben zuzulegen gndgst Rescriptiren wollen, biss dahin dan auch des Hardesvoigten Fedder Lunden Prætension zu ferneren entscheidung ausgesetzet wardt. 